

\title{
An Assessment of the Anatomical Knowledge of Laypersons and their Attitudes toward the Clinical Importance of Gross Anatomy in Medicine
}

\author{
Bernard John Moxham ${ }^{1}$, Helen Hennon ${ }^{1}$, \\ Baptiste Lignier $^{2}$, Odile Plaisant ${ }^{3}$
}

${ }^{1}$ Cardiff School of Biosciences, Cardiff University, Museum Avenue, Cardiff CF10 3AX, United Kingdom

2 Laboratoire de Psychopathologie et Psychologie Médicale (LPPM-EA 4452), Université Bourgogne-Franche Comté, Pole AAFE, Esplanade Erasme, 21000, Dijon, France

${ }^{3}$ University of Paris Descartes, Sorbonne Paris Cité, ANCRE, URDIA, EA 4465, Paris, France

e-mail: moxham@cardiff.ac.uk

Telephone: +44 (0)29 20874031

Fax: +44 (0)29 20875964

Address of correspondence: Professor B J Moxham

Cardiff School of Biosciences

Cardiff University

Museum Avenue

Cardiff CF10 3AX

United Kingdom

Short title: Laypersons and Anatomy 


\begin{abstract}
If it is accepted that increasingly we live within a consumerist society then axiomatically 'ownership' of medical training does not belong to political authorities (whether governmental or medical), nor to the medical profession, nor indeed to the teachers, educationalists and even the students but to the laypersons in society who are patients or potential patients (viz. the clients/recipients of medical care). As yet, however, there has been no attempt to evaluate how much anatomy laypersons know and what their attitudes are towards the importance of anatomy in medicine. By means of a questionnaire, we have conducted a survey of laypersons' attitudes to anatomy in the U.K. and France. Results suggest that, regardless of gender, age, socioeconomic groupings, level of education, or in the presence of some cultural differences between the U.K. and France, laypersons have a reasonable understanding and knowledge of gross anatomy (being weakest on understanding function) and have strong beliefs that gross anatomy is crucial for medical education, holding the view that the medical profession's esteem would be diminished if anatomy were not a significant part of the medical curriculum and if human cadaveric material was not employed in medical training. Thus, laypersons' perceptions about the importance of gross anatomy should be factored into the organisation of medical training, not just to provide important information and skills for future medical/surgical practitioners, but also to help maintain the esteem of the medical profession.
\end{abstract}




\section{Introduction}

There have been many reports showing that the amount and type of teaching of gross anatomy in the medical curriculum has changed radically during recent times (e.g. Monkhouse, 1992 ; Utting and Willan, 1995; Dangerfield et al., 2000, Plaisant et al., 2004; Pryde and Black, 2005, Drake et al., 2002, 2009, 2014). In particular, Drake et al. (2002, 2009,2014 ) found that, within US medical schools, the average number of contact hours devoted to gross anatomy decreased from about 170 hours to 147 hours between 2002 and 2014 and that many course were now part of an integrated curriculum. For the UK, in 1993, 2003, and 2009, the General Medical Council radically altered its guidelines for the training of medical practitioners in the United Kingdom in documents called "Tomorrow's Doctors". A key issue addressed related to the belief that medical students were being overloaded with facts and were, therefore, not being adequately equipped to interact effectively with patients. This led to significant decreases in the amount of anatomy and physiology being taught in medical school. Regarding changes to the methods of teaching of gross anatomy, to accommodate significant cuts to the time spent teaching anatomy, and to change from dissection of cadavers, medical schools have employed other methods such as didactic teaching, problem-based learning (PBL), use of prosections, teaching with models and plastinated specimens, and computer-based programs, living and radiological/medical imaging techniques (Reidenberg and Laitman, 2002; Pabst, 2002; Prince et al., 2003; Plaisant et al., 2004; McLachlan, 2004; Hinduja et al., 2005; McLachlan and Pattern, 2006; Patel and Moxham, 2006; Moxham and Moxham, 2007; Winkelmann, 2007; Korf et al., 2008 ; Kerby et al., 2011; Moxham and Plaisant, 2014; Riederer et al., 2015). In particular, it is perceived that the decrease in teaching hours in anatomy has gone alongside a shift from a teacher-centred approach towards a more student-centred approach. An important trend has been the promotion of professionalism within the medical students during anatomy courses (e.g. Camp et al., 2010; Pearson Jr. and Hoagland, 2010; Wittich et al., 2013; Pawlina and Drake, 2015; Harden, 2015) and this has major impact upon how health care works interact with laypersons (patients and potential patients).

In view of the changes in anatomical education, it is important that the clinical relevance of anatomy is assessed objectively, including investigation of attitudes amongst the stakeholders and recipients of medical education. For example, using similar Thurstone and Chave (1951) analyses as employed in the present study, it has been reported that very positive attitudes towards the clinical importance of anatomy has been discerned for professional anatomists, medical students, and dental students (Patel and Moxham, 2006; Moxham and Plaisant, 2007; Moxham and Moxham, 2007 ; Kerby et al., 2011; OlowoOfayoku and Moxham, 2014 ; see also Pabst, 1993 and 2009). It seems to us appropriate now to discover the level of knowledge of gross anatomy held by laypersons (i.e. patients and potential patients) and to assess their attitudes towards the importance of this subject in medical clinical education and practice. To date, these issues have not been investigated and consequently we present here the results of a survey in the United Kingdom and France that used a questionnaire to evaluate how much anatomy is known by the layperson and to find out how relevant anatomy is thought to be to medicine in society today.

Our initial hypotheses are that laypersons have a reasonable general understanding of the anatomy of the human body and believe that a good knowledge of anatomy by medical practitioners is essential. We also hypothesise that without a good knowledge of human anatomy, and without training using dissection of human cadavers, the public would consider that the medical profession would have a diminished esteem. 


\section{Methods}

Five hundred and five questionnaires were distributed to members of the general public for this survey, with two hundred and eighty three responses (101 from the U.K. and 182 from France) giving a response rate of $56 \%$. In order to get respondents that were unknown to the investigators, we adopted the following methodology. Medical students in both the U.K. and France were provided with questionnaires, 10 for each student enrolled. Each student was clearly instructed in how to further distribute these questionnaires to members of the general public where they lived. It was particularly emphasised that the questionnaires must not be given to friends and relatives and also not to persons who had connections with the health care professions. Within the questionnaire there was a question relating to how the respondents might have knowledge of anatomy and only 4 respondents had some involvement in health care professions and these were not used in the survey.

The questionnaire consisted of 4 sections. Section A contained a set of introductory questions to obtain personal information (age, gender, occupation etc.). Section B comprised a set of Thurstone and Chave (1951) attitude analysis questions (Figure 1) where the respondents had to indicate which statements relating to the possible importance of gross anatomy they were in full agreement. Section $\mathrm{C}$ consisted of outlines of the human body where anatomical structures had to be identified (Figure 2 and 3 ) and a brief set of questions asking for the functions of some human organs (Figure 4). Altogether, 19 questions were asked in this section of the questionnaire. Section $D$ asked questions about the importance of anatomy in medical education and within the medical profession.

Thurstone and Chave (1951) analyses involve listing 20 statements that reflect either a positive, negative or indifferent/moderate attitude; the statements being ordered randomly. Each statement in the list was assigned a numerical value by a panel of 50 "judges" not participating in the survey. Each "judge" assigned a value from 1 to 11 to each statement, a score of 11 suggesting that anatomy is unnecessary in clinical medical education and a score of 1 indicating that anatomy is crucially important. Values between 1 and 11 were assigned to indicate different shades of opinion along the possible spectrum of attitudes. From the data obtained from the panel of "judges", a median was taken for each statement. For the layperson participants in the survey, they were unaware of the numerical values assigned to each statement and were required to select only those statements for which they were in complete agreement. Accordingly, a numerical value for attitude could be calculated for each layperson involved in the survey.

To perform statistical analyses on the data obtained in our survey, t-tests were performed to compare differences between total scores and other numerical variables. Chi-squared tests were undertaken in order to compare sample size between groups (mostly between country but also between gender and answers). Analyses using correlations and multiple regressions were performed to assess which attributes (e.g. gender, social status, level of education) were predictors of attitudes towards anatomy or knowledge of anatomy. 


\section{Results}

Tables 1 and 2 provide information concerning the gender and age of those who responded to the questionnaire. Table 3 and 4 report on anatomical experience (discerned from having medical treatment, reading about the human body, watching videos and television programmes) and the level of interest in anatomy of the respondents. As shown from these Tables, statistically there is no significant difference between gender and country $\left(\mathrm{Chi}^{2}=\right.$ $0.08 ; p>0.05)$. Most of respondents were between 20 to 30 years old $(27.6 \%)$ and between 50 to 60 years old $(23.3 \%)$. There is also no significant difference between country in relation to defining the meaning of 'anatomy' $(p>0.05), 98.2 \%$ correctly defining 'anatomy' in the U.K. and $93.9 \%$ in France. However, there is a significant difference between the U.K. and France with respect to the interest in anatomy, U.K. respondents being more interested than the French $(p<0.05)$.

In terms of their knowledge of gross anatomy, Figure 5 displays the number of questions correctly answered (scores out of 19) and shows that, for the U.K. sample, the range extended from 5 to 19 correct answers with a mean score of 13.1. For the French sample, the range extended from 1 to 19 with a mean score of 11.9. Tables 5 and 6 show a breakdown of the data for this section of the questionnaire. From Table 5, the total scores are higher for U.K. respondents than for French respondents, suggesting that the U.K. respondents have a better anatomical knowledge and this is supported statistically $(p<0.05$ for scores related to identifying and locating anatomical structures; $p<0.05$ for scores concerned with functional anatomy, and $p<0.05$ for total scores). From Table 6 , the significant differences show that U.K. respondents had better knowledge about the kidneys $(p<0.05)$, the location of the parotid gland $(p<0.05)$ and of the diaphragm $(p<0.05)$ and for the 4 questions on functional anatomy ( $p<0.05$ in all instances) while the French respondents had better knowledge about the sciatic nerve $(p<0.05)$.

From the Thurstone and Chave attitude analyses (Figure 6), both U.K. and French respondents had very positive attitudes toward the clinical importance of gross anatomy, with the mean attitude score for the U.K. (2.4) being slightly more positive than for the French respondents $(2.7)(p<0.05)$.

Figures 7 to 14 and Table 7 display the findings from Section $D$ of the questionnaire that asked respondents to assess the effects on changing the teaching of anatomy on the esteem of the medical profession. For both U.K. and French respondents, there is a clear belief that decreasing the amount of anatomy in the medical course and not using cadaveric dissection greatly affects the public esteem of the medical profession and leads to more medical accidents. Given that for each question there is a score ranging from 0 to 4 , the total possible score for the 7 questions in this section of the questionnaire is 28 . For the U.K. sample, the total $D$ score ranged from 18 to 28 (with one outlyer on 9 ). For the French sample, the total D scores ranged from 8 to 28 (with one outlyer on 4). The mean scores were 25.1 for the U.K. sample and 22.5 for the French. Statistically, all D scores are significantly different between U.K. and French respondents, with U.K. scores being higher than French scores. Overall, however, the high total D scores suggest a firm view that the medical profession's esteem requires a commitment to a significant level of anatomical teaching.

Analyses using correlations and multiple regressions to assess which attributes were predictors of attitudes towards anatomy or knowledge of anatomy (Figure 8) produced the 
following findings. First, 'interest for anatomy' increases with respondents' age but is not correlated with the Thurstone and Chave score that indicates attitudes toward the clinical importance of anatomy. Furthermore, the total Section D score is not correlated with the $C$ scores that signify the level of anatomical knowledge. However, 'interest for anatomy' can be predicted by the total $D$ score $(p=0.17)$, by the score for knowledge of functional anatomy $(p=0.15)$, by the total score for anatomical knowledge $(p=0.15)$ and then by gender $(p=0.12)$. This finding nevertheless only explains $12 \%$ of the total variance we observed, meaning that $88 \%$ of the 'interest in anatomy' can be predicted by other variables/attributes we have yet to investigate. Indeed, those most showing 'interest in anatomy' were those with the higher levels of anatomical knowledge and greater concerns for the status of anatomy in the medical curriculum. Second, Thurstone and Chave scores can be predicted (but with negative relationships) by the scores for functional anatomy and for the total scores obtained for section $D$ of the questionnaire where the esteem of the medical profession was gauged with changes in anatomy teaching. Indeed, the lower the scores respondents got for the questions on functional anatomy and for the total section $\mathrm{D}$ score, the higher score they are likely to get on the Thurstone and Chave attitude scale. This suggests that poorer knowledge of functional anatomy and/or little concern for the esteem of the medical profession with changes in anatomy teaching, the more negative is their attitude towards the clinical relevance of anatomy. Third, knowledge of anatomy and location of anatomical structures can be predicted by the level of 'interest' and by age. In addition, understanding of functional anatomy can be predicted by the 'interest for anatomy' $(p=0.25)$ and by the Thurstone and Chave attitude score $(p=-0.16)$. Respondents who have a higher score for 'interest for anatomy' have also a higher score for the section on functional anatomy. However, respondents who have higher scores on the Thurstone and Chave attitude scale (having more negative opinions concerning anatomy's clinical importance) have lower scores for functional anatomy (and vice-versa). Fourth, high scores for anatomical knowledge can be predicted by higher scores on 'interest' $(p=0.24)$, by male gender $(p=0.13)$, and by lower scores on Thurstone and Chave scale indicating positive attitudes towards anatomy's clinical importance $(p=-0.13)$. Fifth, the total $D$ Score relating the esteem for the medical profession with changes to anatomy tuition can be predicted by age (older respondents being more concerned), by lower scores on the Thurstone and Chave scale showing positive attitudes, and by female gender. However, these variables can only explain $10 \%$ of the total variance within the total D Score so that $90 \%$ is related to factors as yet not investigated.

\section{Discussion}

This report is the first to record attitudes of laypersons outside of the healthcare professions to the importance of anatomy. The survey of samples of the population in the U.K. and France enabled a comparison to be made between two European cultures with different ways of ensuring health care provision. Indeed, while some differences were recorded between the samples, overall similar conclusions can be derived for both the U.K. and French samples. The total number of responses to our questionnaire (283) highlight the difficulties of conducting surveys in this area; we anticipate (and would hope for) similar studies to be conducted in the future in different parts of the world to assess the reliability of the outcomes. That said, we were gratified to see that throughout there were consistent findings and clear conclusions to be drawn. First, laypersons are interested in anatomy, have a reasonable knowledge of anatomy, and appreciate anatomy's clinical relevance. Second, laypersons would lose confidence in the medical profession if they understood that 
less anatomy was being taught within the medical curriculum and if there was no dissection of human cadavers offered for medical and surgical training. These conclusions support our initial hypotheses.

Our findings and conclusions highlight two important issues that confront modern medicine in contemporary society. There is the matter of dealing with an increasing 'consumerist' society and issues around the extent to which medical courses are organised from within the medical profession (increasingly by medico-political authorities (e.g. Deans) and by medical educationalists) without cognisance of the needs and attitudes of stakeholders such as society in general and also the individual within society. It is legitimate to ask, therefore, how are the medico-political authorities to be made aware of the attitudes of laypersons? There are umbrella organisations for anatomical societies (e.g. the European Federation for Experimental Morphology in Europe and the International Federation of Associations of Anatomists globally) and these have the wherewithal to deal directly or indirectly (via constituent member anatomical societies) with the authorities to promulgate the results of studies such as the present one.

We live increasingly within a consumerist society where governmental policies are aimed at encouraging the acquisition of services and goods and where these are regulated in the interests of the general public. In our daily lives we are, for better or for worse, exposed to mass consumerism and product placement in the Western World and the line between information, entertainment and product promotion has become blurred. Indeed, people appear to be conforming to consumerist behaviour. More advantageously, in a consumerist society the client (the patient or prospective patient in terms of health care) would be expected to have a major stake in the way in which the services are provided. For medicine, this would entail both indirect influence by way of lobbying government and affecting their policies at elections and direct influence upon the medical profession by means of opinion polls and even through complaints and disciplinary procedures. As yet, the public has had relatively little influence upon medical education and examinations. Despite the clear wish of the public to have a greater say in the way their health services are organised, and also in terms of the 'ownership' of their own bodies, we presently know little about the attitudes of the public to various aspects of medical education and training. This is perhaps surprising given that anecdotally it is often said that the public is getting better educated about health related matters (if only from searching through the internet).

So how would one expect medical curricula to be organised as society takes on a more transparent, democratic and consumerist guise? For many centuries past, the medical profession itself has taken a "top-down" approach towards the training of medical students. As illustrated schematically in Figure 15, the medical profession, organised by a centralised body (e.g. a Committee of Deans or a General Medical Council), delivers pronouncements with various levels of detail about the nature of medical education and training. These pronouncements are then 'translated' by the Deans and medical educationalists to produce a medical curriculum that is delivered to the medical students and who then pass on their abilities to the patients. Within the consumerist ideology, the patient consumers should be at the top of the process and not the mere recipients of the process. Our results confirm that, as laypersons become more knowledgeable about medical and anatomical matters, and as they become more conscious of their rights and status as consumers, they could become more involved (and demanding) of the care they receive from healthcare professionals so that they might not remain merely as passive receivers of the ministrations of medical 'experts'. Thus, the attitudes of laypersons should not be summarily dismissed 
as being of little relevance or of being politically inconsequential. As one of the respondents in the U.K. survey wrote: "If I take my car to a mechanic I assume he knows what's under the bonnet and in the engine, I would similarly expect my doctor to have a good level of knowledge about the anatomy of my internal body". Accordingly, our findings indicate that laypersons would not expect anatomy to be downgraded significantly within the medical curriculum but should remain a fundamental attribute of good medical education. 


\section{References}

Camp, C.L., Gregory, J.K., Lachman, N., Chen, L.P., Juskewitch, J.E., Pawlina, W., 2010. Comparative efficacy of group and individual feedback in gross anatomy for promoting medical student professionalism. Anat. Sci. Educ. 3, 64-72.

Dangerfield, P.H., Bradley, P., Gibbs, T., 2000. Learning gross anatomy in a clinical skills course. Clin. Anat. 13, 444-447.

Drake, R.L., Lowrie, D.J., Prewitt, C.M., 2002. Survey of gross anatomy, microscopic anatomy, neuroscience, and embryology courses in medical school curricula in the United States. Anat. Rec. 269, 118-122.

Drake, R.L., McBride, J.M., Lachman, N., Pawlina, W., 2009. Medical education in the anatomical sciences: The winds of change continue to blow. Anat. Sci. Edu. 2, 253-259.

Drake, R.L., McBride, J.M., Pawlina, W., 2014. An update on the status of anatomical sciences education in United States medical schools. Anat. Sci. Edu. 7, 321-325.

Harden, RM., 2015. Interprofessional education: The magical mystery tour now less of a mystery. Anat. Sci. Educ. 8, 291-5.

Hinduja, K., Samuel, R., Mitchell, S., 2005. Problem-based learning: Is anatomy a casualty? Surgeon 3, 84-87.

Kerby, J., Shukur, Z.N., Shalhoub, J., 2011. The relationships between learning outcomes and methods of teaching anatomy as perceived by medical students. Clin. Anat. 24, 489497.

Korf, H-W., Wicht, H., Snipes R.L., Timmermans, J-P., Paulsen, F., Rune, G., BaumgartVogt, E., 2008. The dissection course - necessary and indispensable for teaching anatomy to medical students. Ann. Anat. 190, 16-22.

McLachlan, J.C., 2004. New path for teaching anatomy: living anatomy and medical imaging vs. dissection. Anat. Rec. B New Anat. 281, 4-5.

McLachlan, J.C., Patten D., 2006. Anatomy teaching: ghosts of the past, present and future. Med. Educ. 40, 243-53.

Monkhouse, W.S., 1992. Anatomy and the medical school curriculum. Lancet 340, 834-835.

Pearson, W.G. Jr., Hoagland, T.M., 2010. Measuring change in professionalism attitudes during the gross anatomy course. Anat. Sci. Educ. 3, 12-6.

Moxham, B.J., Moxham, S.A., 2007. The relationships between attitudes, course aims and teaching methods for the teaching of gross anatomy in the medical curriculum. Eur. J. Anat., 11, 19-30. 
Moxham, B.J., Plaisant, O., 2007. Perception of medical students towards the clinical relevance of anatomy. Clin. Anat. 20, 560-564.

Moxham, B.J., Plaisant, O., 2014. The History of the Teaching of Gross Anatomy How we got to where we are! Eur. J. Anat.18, 217-242.

Olowo-Ofayoku, A., Moxham, B.J., 2014. Comparisons between the attitudes of medical and dental students toward the clinical importance of gross anatomy and physiology. Clin. Anat. 27, 976-987.

Pabst, R., 2002. Modern macroscopic anatomy-more than just cadaver dissection. Anat. Rec. 269, 209.

Pabst, R., 1993. Gross anatomy: an outdated subject or an essential part of a modern medical curriculum? Results of a questionnaire circulated to final-year medical students. Anat. Rec. 237, 431-3.

Pabst, R., 2009. Anatomy curriculum for medical students: what can be learned for future curricula from evaluations and questionnaires completed by students, anatomists and clinicians in different countries? Ann. Anat. 191, 541-6.

Patel, K.M., Moxham, B.J., 2006. Attitudes of professional anatomists to curricular change. Clin. Anat. 19, 132-141.

Pawlina, W., Drake, R.L., 2015. Interprofessional education: First steps. Anat. Sci. Educ. 8, 289-90.

Plaisant, O., Cabanis, E.A., Delmas, V., 2004. Going back to dissection in a medical curriculum: the paradigm of Necker-Enfants Malades. Surg. Radiol. Anat. 26, 504- 511.

Prince, K., van Mameren. H., Hylkema, N., Drukker, J., Scherpbier, A., van der Vleuten, C., 2003. Does problem based learning lead to deficiencies in basic science knowledge? An empirical case on anatomy. Med. Educ. 35, 15-21.

Pryde, F.R., Black, S.M., 2005. Anatomy in Scotland: 20 years of change. Scott. Med. J. 50, 96-98.

Reidenberg, J.S., Laitman, J.T., 2002. The new face of gross anatomy. Anat. Rec. 269, 818.

Riederer, B.M., Bueno-López, J.L., Ayer, R., Reblet, C., Cadas, H., Puyal, J.P., 2015. Practical teaching of preclinical anatomy. Eur. J. Anat. 19, 205-213.

Thurstone, L.L., Chave, E.J., 1951. The measurement of attitude; a psychophysical method and some experiments with a scale for measuring attitude toward the church. Chicago, III.: University of Chicago Press.

Utting, M., Willan, P., 1995. What future for dissection in courses of human topographical anatomy in universities in the UK? Clin. Anat. 8, 414-417. 
Waterson, S.W., Stewart, I.J., 2005. Survey of clinician's attitudes to the anatomical teaching and knowledge of medical students. Clin. Anat. 18, 380-384.

Winkelmann, A., 2007. Anatomical dissection as a teaching method in medical school: a review of the evidence. Medic. Educ. 41, 15-22.

Wittich, C.M., Pawlina, W., Drake, R.L., Szostek, J.H., Reed, D.A., Lachman, N., McBride, J.M., Mandrekar, J.N., Beckman, T.J., 2013. Validation of a method for measuring medical students' critical reflections on professionalism in gross anatomy. Anat. Sci. Educ. 6, 232-8.

Tables

Table 1: Gender of respondents

\begin{tabular}{|l|l|l|}
\hline Gender & Number & Frequency \\
\hline Female & 153 & $54.1 \%$ \\
\hline Male & 130 & $45.9 \%$ \\
\hline Total & 283 & $100 \%$ \\
\hline
\end{tabular}

\begin{tabular}{|l|c|c|l|}
\hline Gender & FR & U.K. & Total \\
\hline Female & 100 & 53 & 153 \\
\hline Male & 82 & 48 & 130 \\
\hline Total & 182 & 101 & 283 \\
\hline
\end{tabular}

Table 2: Age of respondents

\begin{tabular}{|l|l|l|l|l|l|l|}
\hline & Number & Frequency & FR & \multicolumn{3}{l|}{ U.K. } \\
\hline Under 20 & 19 & $6.7 \%$ & 11 & $6.0 \%$ & 8 & $7.9 \%$ \\
\hline $\mathbf{2 0 - 3 0}$ & 78 & $27.6 \%$ & 61 & $33.5 \%$ & 17 & $16.8 \%$ \\
\hline $\mathbf{3 0 - 4 0}$ & 35 & $12.4 \%$ & 21 & $11.5 \%$ & 14 & $13.9 \%$ \\
\hline $\mathbf{4 0 - 5 0}$ & 46 & $16.3 \%$ & 31 & $17.0 \%$ & 15 & $14.9 \%$ \\
\hline $\mathbf{5 0 - 6 0}$ & 66 & $23.3 \%$ & 36 & $19.8 \%$ & 30 & $29.7 \%$ \\
\hline $\mathbf{6 0}+$ & 39 & $13.8 \%$ & 22 & $12.1 \%$ & 17 & $16.8 \%$ \\
\hline Total & 283 & $100 \%$ & 182 & $100 \%$ & 101 & $100 \%$ \\
\hline
\end{tabular}

Table 3: Anatomical experience of respondents

\begin{tabular}{|l|l|l|l|l|l|l|}
\hline & Number & Frequency & FR & U.K. \\
\hline $\mathbf{0}$ & 13 & $4.6 \%$ & 11 & $6.1 \%$ & 2 & $2.0 \%$ \\
\hline $\mathbf{1}$ & 269 & $95.4 \%$ & 170 & $93.9 \%$ & 99 & $98.0 \%$ \\
\hline Total & 282 & $100 \%$ & 181 & $100 \%$ & 101 & $100 \%$ \\
\hline
\end{tabular}

Table 4: Level of interest in anatomy shown by responents

\begin{tabular}{|l|l|l|l|r|l|r|}
\hline & Number & Frequency & FR & U.K. \\
\hline $\mathbf{0}$ & 2 & $0.7 \%$ & 2 & $1.1 \%$ & 0 & $0 \%$ \\
\hline $\mathbf{1}$ & 23 & $8.1 \%$ & 20 & $11.0 \%$ & 3 & $3.0 \%$ \\
\hline
\end{tabular}




\begin{tabular}{|l|l|l|l|l|l|l|}
\hline $\mathbf{2}$ & 105 & $37.1 \%$ & 80 & $44.0 \%$ & 25 & $24.8 \%$ \\
\hline $\mathbf{3}$ & 138 & $48.8 \%$ & 76 & $41.8 \%$ & 62 & $61.4 \%$ \\
\hline $\mathbf{4}$ & 15 & $5.3 \%$ & 4 & $2.2 \%$ & 11 & $10.9 \%$ \\
\hline Total & 283 & $100 \%$ & 182 & $100 \%$ & 101 & $100 \%$ \\
\hline & Mean & SD & $\mathbf{t}$ & $\mathbf{d f}$ & $\mathbf{P}$ & \\
\hline Whole & 2.5 & 0.8 & & & & \\
\hline UK & 2.8 & 0.7 & & & & \\
\hline FR & 2.3 & 0.7 & -5.5 & 227.1 & 0.00 & \\
\hline
\end{tabular}

Table 5: Total scores for Section $C$ that assessed respondents knowledge of gross anatomy (Questions $\mathrm{C} 1$ and $\mathrm{C} 2$ required identification and location of anatomical structures; Questions C3 tested functional anatomy)

\begin{tabular}{cccccc}
\hline Score C1+C2 & Mean & SD & t & df & p \\
\hline Whole & 9.8 & 3.2 & & & \\
U.K. & 10.4 & 2.9 & -2.7 & 233.0 & 0.007473 \\
FR & 9.4 & 3.3 & & & \\
\hline Score C3 & & & & & \\
\hline Whole & 2.4 & 1.0 & & & \\
U.K. & 2.6 & 1.0 & -2.4 & 206.9 & 0.01591 \\
FR & 2.3 & 1.0 & & & \\
\hline Total Score & & & & & \\
\hline Whole & 12.3 & 3.9 & & & \\
U.K. & 13.1 & 3.4 & & & \\
FR & 11.9 & 4.0 & -2.7 & 236.0 & 0.007839 \\
\hline
\end{tabular}

Table 6: Section C scores concerned with the assessment of the knowledge of anatomy (Questions C1a to C1i required respondents to identify labelled structures on a diagram; Questions C2.1 to C2.6 required respondents to locate anatomical structures on a diagram outlining the human body; C3i to C3iv required identification of the functions of 4 organs)

\begin{tabular}{|c|c|c|c|c|c|c|}
\hline \multirow[t]{2}{*}{ C1a } & \multirow{2}{*}{$\begin{array}{l}\mathrm{N} \\
4\end{array}$} & \multirow{2}{*}{$\begin{array}{c}\text { Frequency } \\
1.4 \%\end{array}$} & \multicolumn{2}{|c|}{ FR } & \multicolumn{2}{|c|}{ U.K. } \\
\hline & & & 4 & $2.2 \%$ & 0 & 0 \\
\hline 1 & 279 & $98.6 \%$ & 178 & $97.8 \%$ & 101 & $100 \%$ \\
\hline Total & 283 & $100 \%$ & 182 & $100 \%$ & 101 & $100 \%$ \\
\hline \multicolumn{7}{|l|}{ C1b } \\
\hline 0 & 120 & $42.4 \%$ & 82 & $45.1 \%$ & 38 & $37.6 \%$ \\
\hline 1 & 163 & $57.6 \%$ & 100 & $55.0 \%$ & 63 & $62.4 \%$ \\
\hline Total & 283 & $100 \%$ & 182 & $100 \%$ & 101 & $100 \%$ \\
\hline \multicolumn{7}{|l|}{ C1c } \\
\hline 0 & 164 & $58.0 \%$ & 112 & $61.5 \%$ & 52 & $51.5 \%$ \\
\hline 1 & 119 & $42.1 \%$ & 70 & $38.5 \%$ & 49 & $48.5 \%$ \\
\hline Total & 283 & $100 \%$ & 182 & $100 \%$ & 101 & $100 \%$ \\
\hline \multicolumn{7}{|l|}{ C1d } \\
\hline 0 & 59 & $20.9 \%$ & 41 & $22.5 \%$ & 18 & $17.8 \%$ \\
\hline 1 & 224 & $79.2 \%$ & 141 & $77.5 \%$ & 83 & $82.2 \%$ \\
\hline Total & 283 & $100 \%$ & 182 & $100 \%$ & 101 & $100 \%$ \\
\hline \multicolumn{7}{|l|}{ C1e } \\
\hline 0 & 144 & $50.9 \%$ & 99 & $54.4 \%$ & 45 & $44.6 \%$ \\
\hline 1 & 139 & $49.1 \%$ & 83 & $45.6 \%$ & 56 & $55.4 \%$ \\
\hline Total & 283 & $100 \%$ & 182 & $100 \%$ & 101 & $100 \%$ \\
\hline C1f & & & & & & \\
\hline
\end{tabular}




\begin{tabular}{|c|c|c|c|c|c|c|}
\hline $\begin{array}{c}0 \\
1 \\
\text { Total } \\
\end{array}$ & $\begin{array}{l}173 \\
110 \\
283 \\
\end{array}$ & $\begin{array}{c}61.1 \% \\
38.9 \% \\
100 \% \\
\end{array}$ & $\begin{array}{c}118 \\
64 \\
182 \\
\end{array}$ & $\begin{array}{c}64.8 \% \\
35.2 \% \\
100 \% \\
\end{array}$ & $\begin{array}{c}55 \\
46 \\
101 \\
\end{array}$ & $\begin{array}{c}54.5 \% \\
45.5 \% \\
100 \% \\
\end{array}$ \\
\hline \multicolumn{7}{|l|}{ C1g } \\
\hline 0 & 24 & $8.5 \%$ & 16 & $8.8 \%$ & 8 & $7.9 \%$ \\
\hline 1 & 259 & $91.5 \%$ & 166 & $91.2 \%$ & 93 & $92.1 \%$ \\
\hline Total & 283 & $100 \%$ & 182 & $100 \%$ & 101 & $100 \%$ \\
\hline \multicolumn{7}{|l|}{ C1h } \\
\hline 0 & 92 & $32.5 \%$ & 79 & $43.4 \%$ & 13 & $12.9 \%$ \\
\hline 1 & 191 & $67.5 \%$ & 103 & $56.6 \%$ & 88 & $87.1 \%$ \\
\hline Total & 282 & $100 \%$ & 182 & $100 \%$ & 101 & $100 \%$ \\
\hline \multicolumn{7}{|l|}{ C1i } \\
\hline 0 & 102 & $36.0 \%$ & 85 & $46.7 \%$ & 17 & $16.8 \%$ \\
\hline 1 & 181 & $64.0 \%$ & 97 & $53.3 \%$ & 84 & $83.2 \%$ \\
\hline Total & 283 & $100 \%$ & 182 & $100 \%$ & 101 & $100 \%$ \\
\hline \multicolumn{7}{|l|}{ C2.1 } \\
\hline 0 & 218 & $77.0 \%$ & 148 & $81.3 \%$ & 70 & $69.3 \%$ \\
\hline 1 & 65 & $23.0 \%$ & 34 & $18.7 \%$ & 31 & $30.7 \%$ \\
\hline Total & 283 & $100 \%$ & 182 & $100 \%$ & 101 & $100 \%$ \\
\hline \multicolumn{7}{|l|}{ C2.2 } \\
\hline 0 & 130 & $45.9 \%$ & 91 & $50.00 \%$ & 39 & $38.6 \%$ \\
\hline 1 & 153 & $54.1 \%$ & 91 & $50.00 \%$ & 62 & $61.4 \%$ \\
\hline Total & 283 & $100 \%$ & 182 & $100 \%$ & 101 & $100 \%$ \\
\hline \multicolumn{7}{|l|}{ C2.3 } \\
\hline 0 & 44 & $15.6 \%$ & 27 & $14.8 \%$ & 17 & $16.8 \%$ \\
\hline 1 & 239 & $84.5 \%$ & 155 & $85.2 \%$ & 84 & $83.2 \%$ \\
\hline Total & 283 & $100 \%$ & 182 & $100 \%$ & 101 & $100 \%$ \\
\hline \multicolumn{7}{|l|}{ C2.4 } \\
\hline 0 & 44 & $15.6 \%$ & 35 & $19.2 \%$ & 9 & $8.9 \%$ \\
\hline 1 & 239 & $84.5 \%$ & 147 & $80.8 \%$ & 92 & $91.1 \%$ \\
\hline Total & 283 & $100 \%$ & 182 & $100 \%$ & 101 & $100 \%$ \\
\hline \multicolumn{7}{|l|}{ C2.5 } \\
\hline 0 & 74 & $26.3 . \%$ & 52 & $28.9 \%$ & 22 & $21.8 \%$ \\
\hline 1 & 207 & $73.7 \%$ & 128 & $71.1 \%$ & 79 & $78.2 \%$ \\
\hline Total & 281 & $100 \%$ & 180 & $100 \%$ & 101 & $100 \%$ \\
\hline \multicolumn{7}{|l|}{ C2.6 } \\
\hline 0 & 97 & $34.5 \%$ & 35 & $19.4 \%$ & 62 & $61.4 \%$ \\
\hline 1 & 184 & $65.5 \%$ & 145 & $80.6 \%$ & 39 & $38.6 \%$ \\
\hline Total & 281 & $100 \%$ & 180 & $100 \%$ & 101 & $100 \%$ \\
\hline \multicolumn{7}{|l|}{ C3i } \\
\hline 0 & 14 & $5.0 \%$ & 14 & $7.7 \%$ & 0 & $0 \%$ \\
\hline 1 & 269 & $95.1 \%$ & 168 & $92.1 \%$ & 101 & $100 \%$ \\
\hline Total & 283 & $100 \%$ & 182 & $100 \%$ & 101 & $100 \%$ \\
\hline \multicolumn{7}{|l|}{ C3ii } \\
\hline 0 & 82 & $29.0 \%$ & 38 & $20.9 \%$ & 44 & $43.6 \%$ \\
\hline 1 & 201 & $71.0 \%$ & 144 & $79.1 \%$ & 57 & $56.4 \%$ \\
\hline Total & 283 & $100 \%$ & 182 & $100 \%$ & 101 & $100 \%$ \\
\hline \multicolumn{7}{|l|}{ C3iii } \\
\hline 0 & 135 & $47.7 \%$ & 97 & $53.3 \%$ & 38 & $37.6 \%$ \\
\hline 1 & 148 & $52.3 \%$ & 85 & $46.7 \%$ & 63 & $62.4 \%$ \\
\hline Total & 283 & $100 \%$ & 182 & $100 \%$ & 101 & $100 \%$ \\
\hline \multicolumn{7}{|l|}{ C3iv } \\
\hline 0 & 211 & $74.6 \%$ & 155 & $85.2 \%$ & 56 & $55.4 \%$ \\
\hline 1 & 72 & $25.4 \%$ & 27 & $14.8 \%$ & 45 & $44.6 \%$ \\
\hline Total & 283 & $100 \%$ & 182 & $100 \%$ & 101 & $100 \%$ \\
\hline
\end{tabular}


Table 7: Section D scores that ask respondents to assess the effects on changing the teaching of anatomy on the esteem of the medical profession

\begin{tabular}{|c|c|c|c|c|c|}
\hline D1 & Mean & SD & $t$ & df & $p$ \\
\hline Whole & 3.2 & 0.7 & & & \\
\hline U.K. & 3.4 & 0.6 & & & \\
\hline FR & 3.2 & 0.8 & -2.2 & 256.6 & 0.0293 \\
\hline \multicolumn{6}{|l|}{ D2 } \\
\hline Whole & 3.7 & 0.9 & & & \\
\hline U.K. & 3.9 & 0.4 & & & \\
\hline FR & 3.5 & 1.1 & -4.2 & 260.3 & 0.000004 \\
\hline \multicolumn{6}{|l|}{ D3 } \\
\hline Whole & 3.1 & 0.8 & & & \\
\hline U.K. & 4.4 & 0.6 & & & \\
\hline FR & 2.9 & 0.8 & -5.8 & 254.8 & 0.000000 \\
\hline \multicolumn{6}{|l|}{ D4 } \\
\hline Whole & 3.7 & 0.9 & & & \\
\hline U.K. & 3.8 & 0.5 & & & \\
\hline FR & 3.6 & 1.1 & -2.8 & 267.6 & 0.005273 \\
\hline \multicolumn{6}{|l|}{ D5 } \\
\hline Whole & 3.0 & 1.0 & & & \\
\hline U.K. & 3.4 & 0.7 & & & \\
\hline FR & 2.9 & 1.0 & -4.8 & 267.3 & 0.0000002 \\
\hline \multicolumn{6}{|l|}{ D6 } \\
\hline Whole & 3.2 & 1.1 & & & \\
\hline U.K. & 3.5 & 0.7 & & & \\
\hline FR & 3.0 & 1.2 & -4.5 & 277.8 & 0.00000008 \\
\hline \multicolumn{6}{|l|}{ D7 } \\
\hline Whole & 3.5 & 0.9 & & & \\
\hline U.K. & 3.7 & 0.7 & & & \\
\hline $\mathrm{FR}$ & 3.4 & 1.0 & -3.1 & 263.8 & 0.002241 \\
\hline \multicolumn{6}{|c|}{ Total D Score } \\
\hline Whole & 23.4 & 4.0 & & & \\
\hline U.K. & 25.1 & 2.7 & & & \\
\hline FR & 22.5 & 4.2 & -6.3 & 271.6 & 0.0000000 \\
\hline
\end{tabular}

Table 8:

Correlations

$\mathrm{n}=278$

\begin{tabular}{|c|c|c|c|c|c|}
\hline & $\begin{array}{l}\text { Age } \\
\text { (Index) }\end{array}$ & Interest & $\begin{array}{l}\text { Thurstone } \\
\text { Score }\end{array}$ & ScoreC1 & ScoreC3 ScoreC \\
\hline \multirow[t]{2}{*}{ Interest for anatomy } & 0.1191 & & & & \\
\hline & $p=0.047$ & & & & \\
\hline \multirow[t]{2}{*}{ Thurstone Score } & -0.1028 & -0.1062 & & & \\
\hline & $p=0.087$ & $p=0.077$ & & & \\
\hline \multirow[t]{2}{*}{ Score C1C2 } & 0.1634 & 0.2317 & -0.1249 & & \\
\hline & $p=0.006$ & $p=0.000$ & $p=0.037$ & & \\
\hline \multirow[t]{2}{*}{ Score C3 } & 0.1293 & 0.2766 & -0.1925 & 0.4549 & \\
\hline & $p=0.031$ & $p=0.000$ & $p=0.001$ & $p=0.000$ & \\
\hline \multirow[t]{2}{*}{ Score C } & 0.1647 & 0.2788 & -0.1546 & 0.9552 & 0.6222 \\
\hline & $p=0.006$ & $p=0.000$ & $p=0.010$ & $p=0.00$ & $p=0.00$ \\
\hline
\end{tabular}


Total D Score

$\begin{array}{llllll}\mathbf{0 . 2 1 3 1} & \mathbf{0 . 1 8 5 8} & \mathbf{- 0 . 2 0 8} & 0.0601 & 0.1042 & 0.0706 \\ \mathbf{p}=\mathbf{0 . 0 0 0} & \boldsymbol{p}=\mathbf{0 . 0 0 2} \boldsymbol{p}=\mathbf{0 . 0 0 0} & \mathrm{p}=0.318 & p=0.083 & p=0.240\end{array}$




\section{Figures}

Figure 1 Statements in the questionnaire used to assess the attitudes of laypersons toward the importance of anatomy in medicine according to the method devised by Thurstone and Chave (1951). In answering the questionnaire, a respondent is required only to indicate which statements he/she is in complete agreement with. Note that the medians provided here for each statement, and obtained independently by the panel of 'judges', were not seen by the responding laypersons.

\begin{tabular}{|c|c|}
\hline statements & Medians \\
\hline $\begin{array}{l}\text { Although anatomy is interesting, the subject needs selective } \\
\text { understanding in the clinic. }\end{array}$ & 7 \\
\hline Anatomical terminology is the vocabulary of medicine. & 2 \\
\hline Anatomy is a useful tool for satisfactory medical practice. & 3 \\
\hline Anatomy is a "necessary evil" in Medicine. & 7 \\
\hline $\begin{array}{l}\text { Anatomy is of some use in the clinic, but its importance may be } \\
\text { exaggerated. }\end{array}$ & 8 \\
\hline Anatomy is only of benefit in certain medical specialities. & 7 \\
\hline $\begin{array}{l}\text { Anatomy is so old fashioned that it has no importance in contemporary } \\
\text { Medicine. }\end{array}$ & 11 \\
\hline Anatomy is time wasted in the medical curriculum. & 11 \\
\hline Anatomy needs to modernise if it is going to be really useful in Medicine. & 6 \\
\hline Every doctor must have a good knowledge of Anatomy. & 2 \\
\hline $\begin{array}{l}\text { If alternative and Eastern Medicine can do without Anatomy, so can } \\
\text { Western Medicine. }\end{array}$ & 10 \\
\hline $\begin{array}{l}\text { It is impossible to conceive of good medical training without a major } \\
\text { Anatomy component. }\end{array}$ & 2 \\
\hline $\begin{array}{l}\text { It is not possible to make a reasonable medical diagnosis without } \\
\text { Anatomy. }\end{array}$ & 2 \\
\hline Medicine could not exist without Anatomy. & 1 \\
\hline Most medical conditions do not require a great knowledge of Anatomy. & 8 \\
\hline Of all the basic sciences, Anatomy is the most relevant & 3 \\
\hline $\begin{array}{l}\text { Only a limited anatomical knowledge is required for satisfactory } \\
\text { medical practice. }\end{array}$ & 7 \\
\hline $\begin{array}{l}\text { Rather than learn Anatomy, medical students should concentrate on } \\
\text { clinical sciences. }\end{array}$ & 9 \\
\hline The principles of Medicine are not founded on anatomical knowledge. & 9 \\
\hline Without a knowledge of Anatomy the doctor is of limited effectiveness. & 3 \\
\hline
\end{tabular}


Figure 2 (Questions from Section C: C1a to C1i that required respondents to identify anatomical structures labelled)

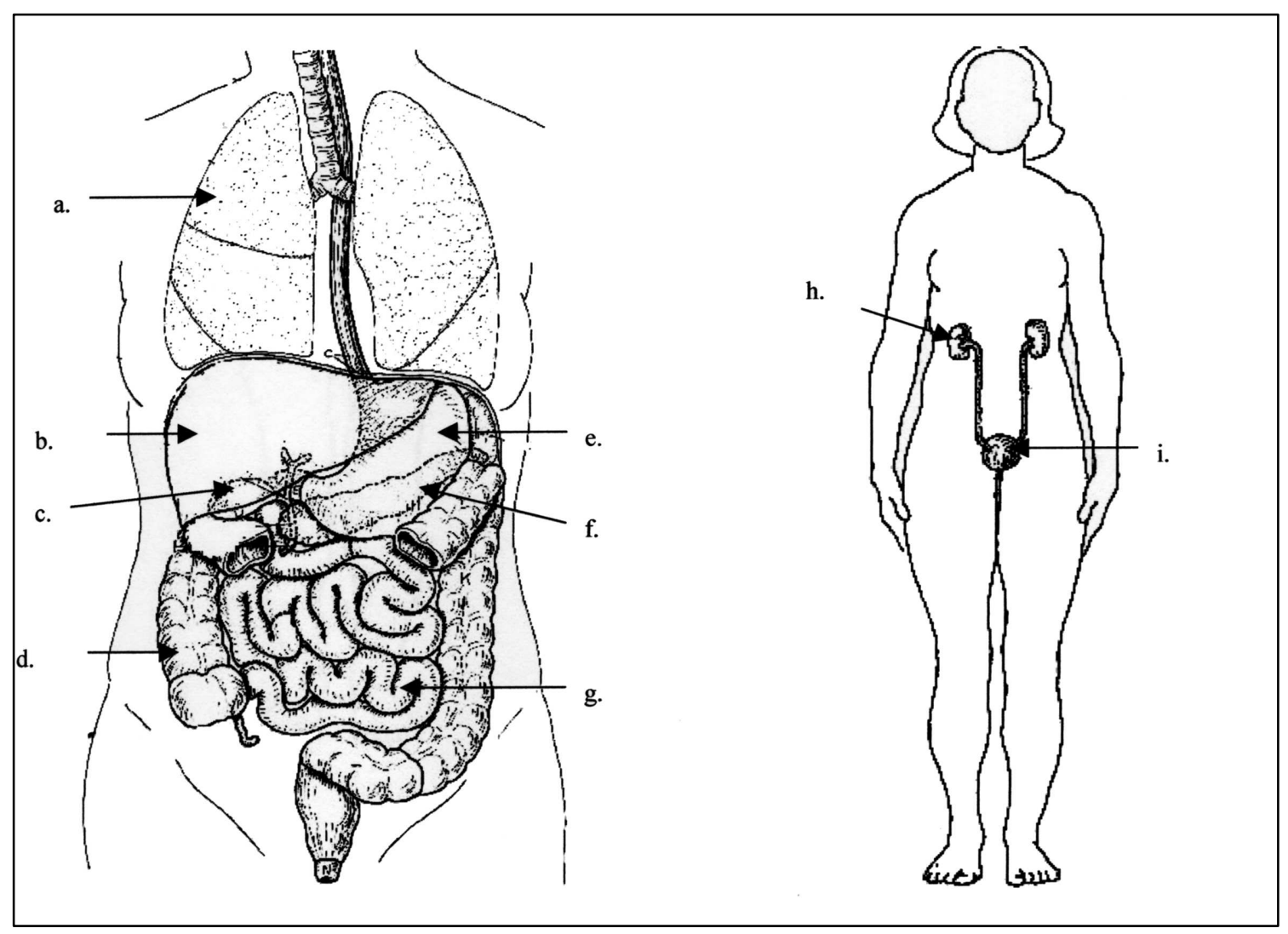


Figure 3 (Questions from Section C: C2.1 to C2.6 that required respondents to mark where 6 anatomical structures would be located)

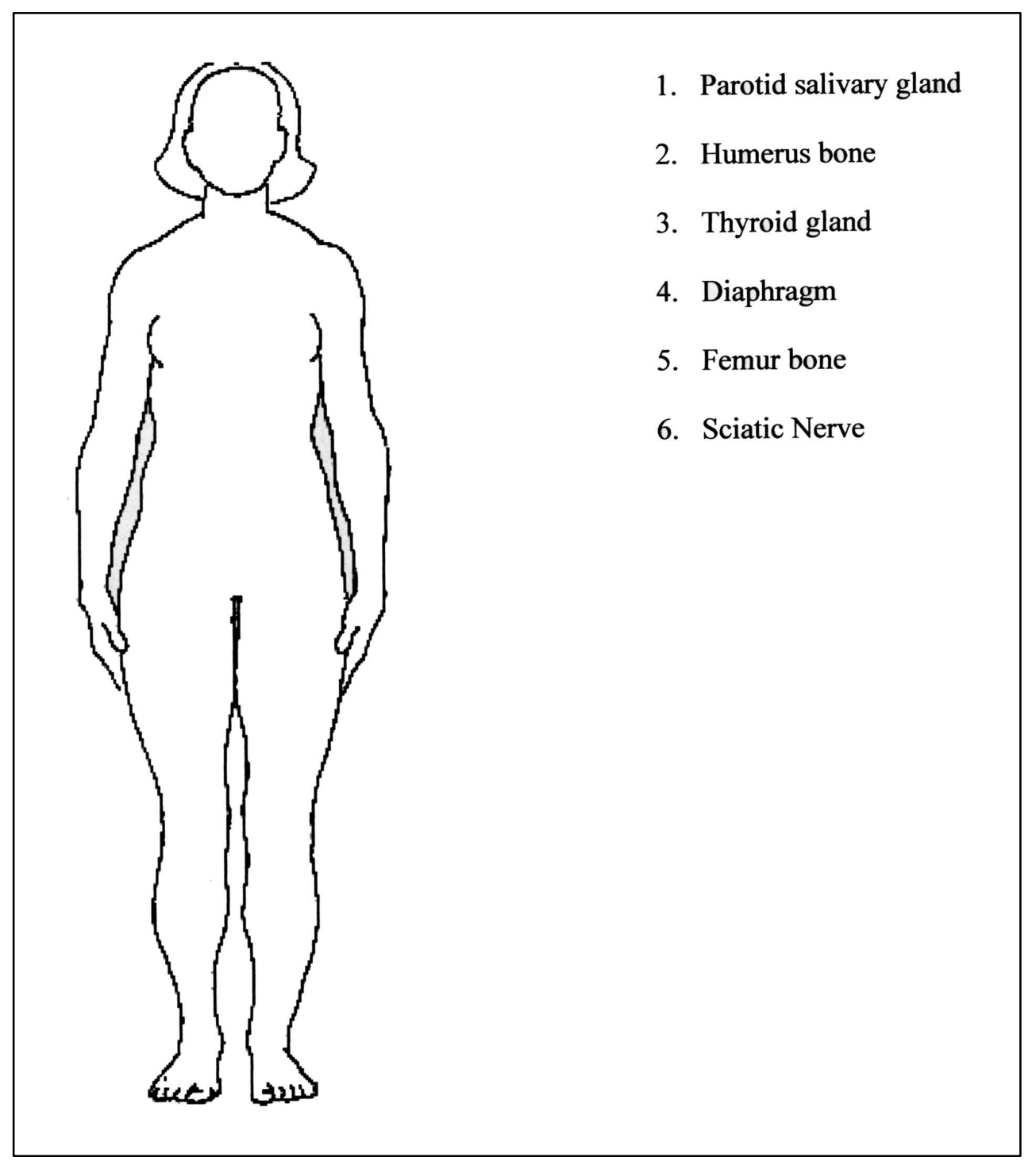

Figure 4 (Questions from Section C: C3i to C3iv that require respondents to state the functions of three organs)

i What are the functions of the heart?

ii What are the functions of the liver?

iii What are the functions of the pancreas?

iv What are the functions of the pituitary gland? 
Figure 5
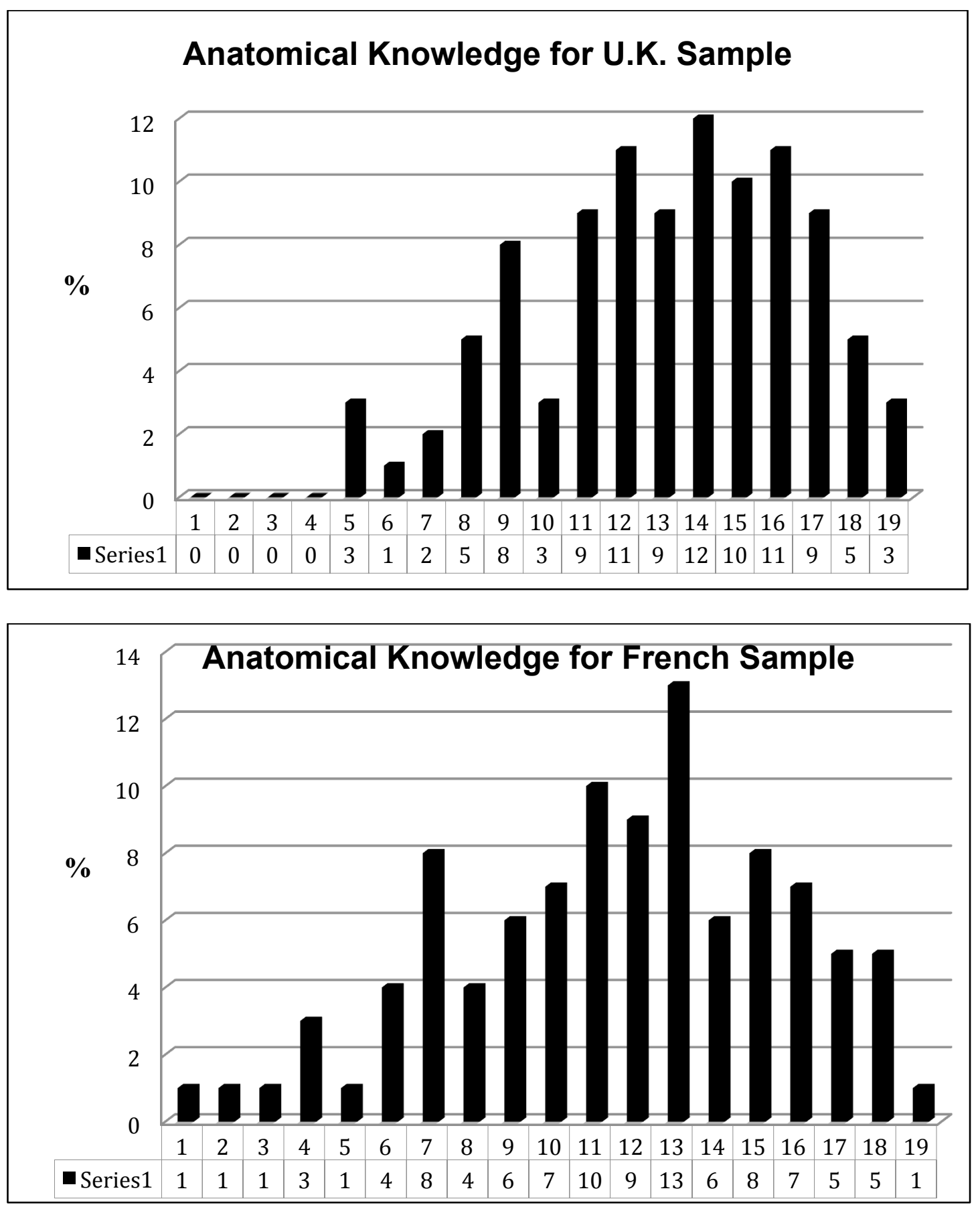

\begin{tabular}{|l|l|l|l|l|l|}
\hline Country & Mean & SD & t & df & p \\
\cline { 1 - 3 } Whole & 12.3 & 3.9 & & & \\
\cline { 1 - 2 } G.K. & 13.1 & 3.4 & & & \\
\hline
\end{tabular}


Figure 6 Attitudes of Laypersons to Anatomy (Black columns = U.K.; Grey columns = France)

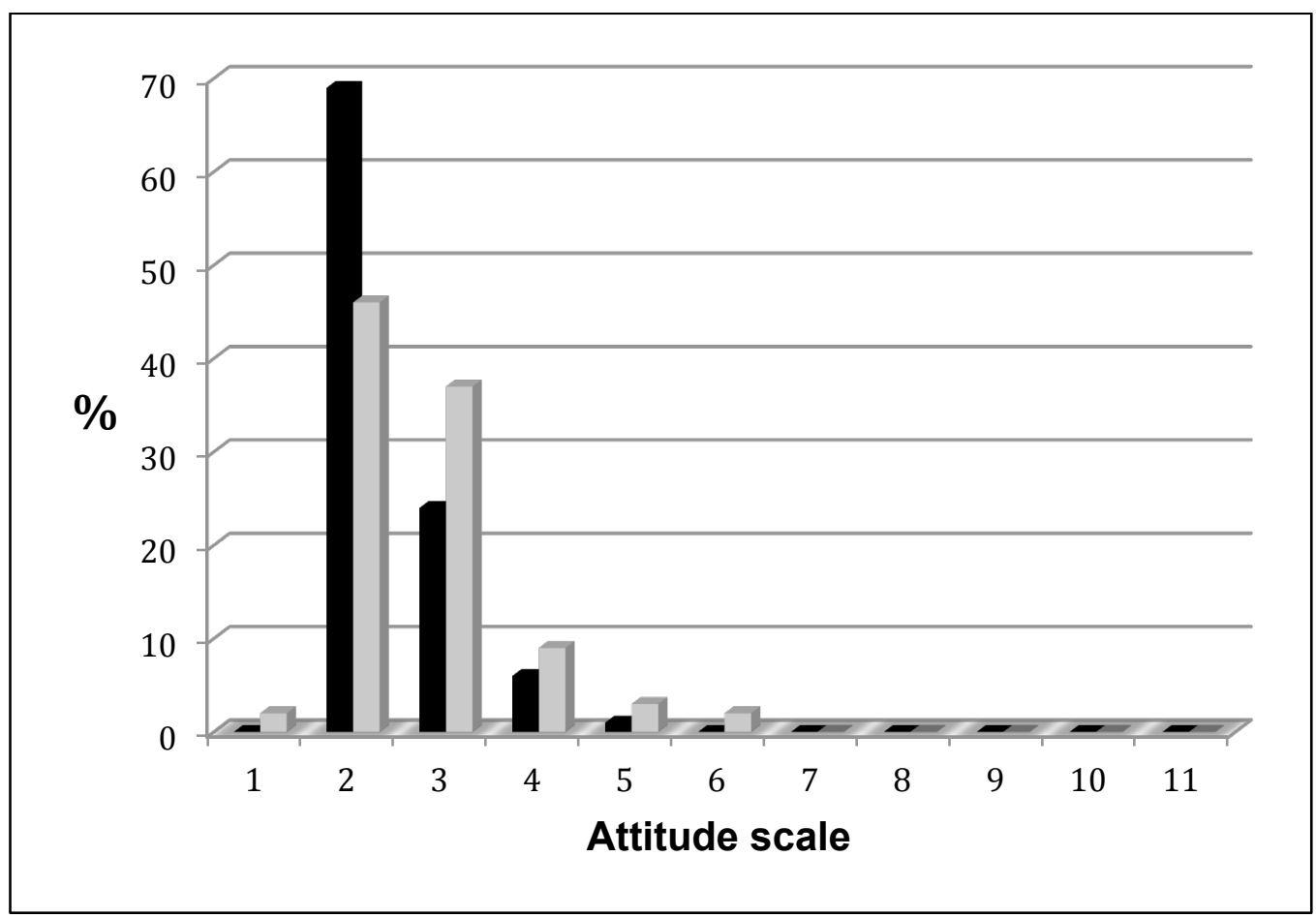

\begin{tabular}{|l|l|l|l|l|l|}
\hline Country & Mean & SD & t & df & p \\
\cline { 1 - 2 } Whole & 2.6 & 0.8 & & & \\
\cline { 1 - 2 } U.K. & 2.4 & 0.7 & & & \\
\hline FR & 2.7 & 0.9 & 3.6 & 261.1 & 0.0004407 \\
\hline
\end{tabular}


Figure 7: Scores for Section D - Question 1 (Black columns = U.K.; Grey columns = France) If you were told that your medical doctor (GP) had much less anatomical training in today's medical course than 20 years ago, would your confidence in him/her be:

Greatly increased (0); Slightly increased (1); Not affected (2); Slightly diminished (3); Greatly diminished (4)

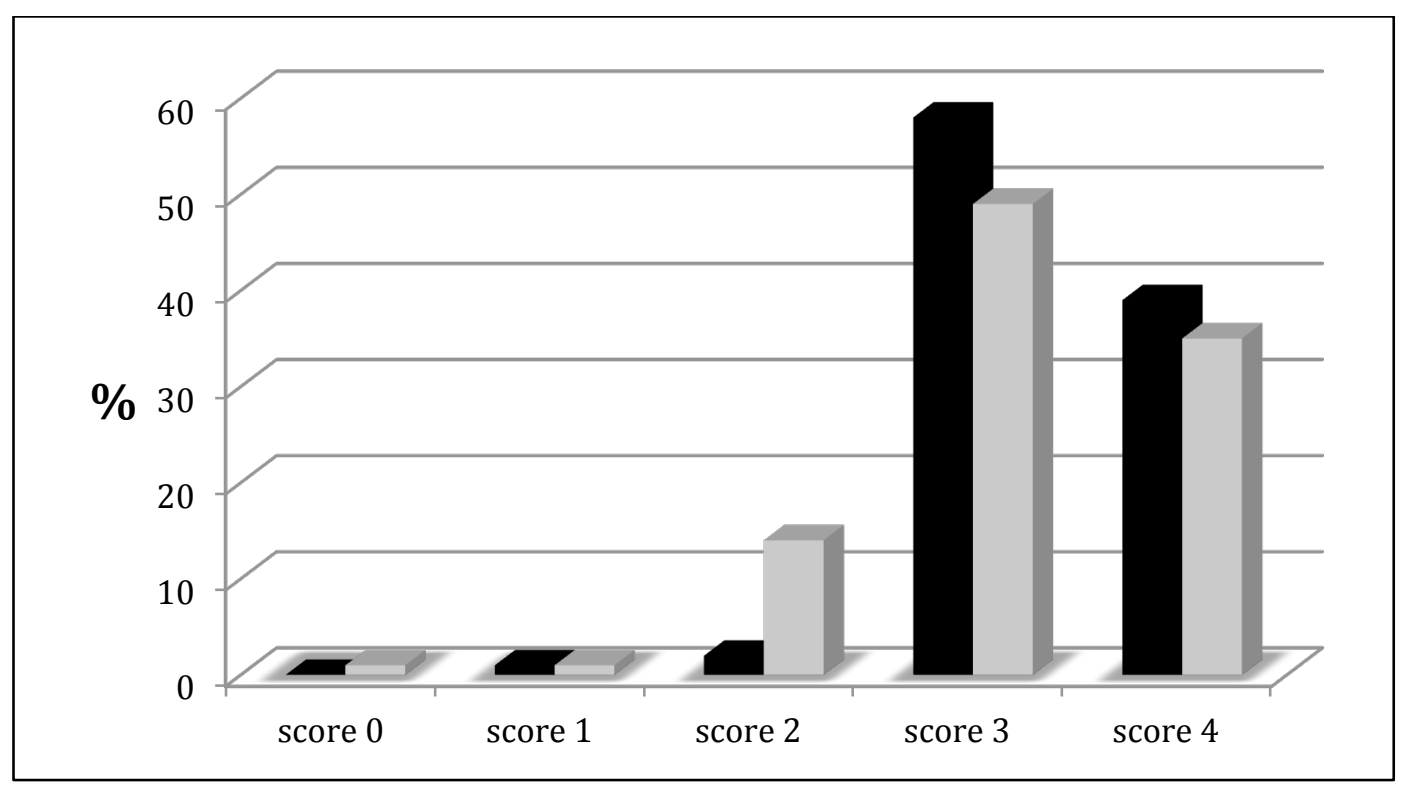

\begin{tabular}{|l|l|l|l|l|l|}
\hline Country & Mean & SD & t & df & p \\
\cline { 1 - 3 } & 3.2 & 0.7 & & & \\
\cline { 1 - 3 } & 3.4 & 0.6 & & & \\
\hline FR & 3.2 & 0.8 & -2.2 & 256.6 & 0.0293 \\
\hline
\end{tabular}


Figure 8: Scores for Section D - Question 2 (Black columns = U.K.; Grey columns = France)

If you were told that your surgeon had much less anatomical training in today's medical course than 20 years ago, would your confidence in him/her be: Greatly increased (0); Slightly increased (1); Not affected (2); Slightly diminished (3); Greatly diminished (4)

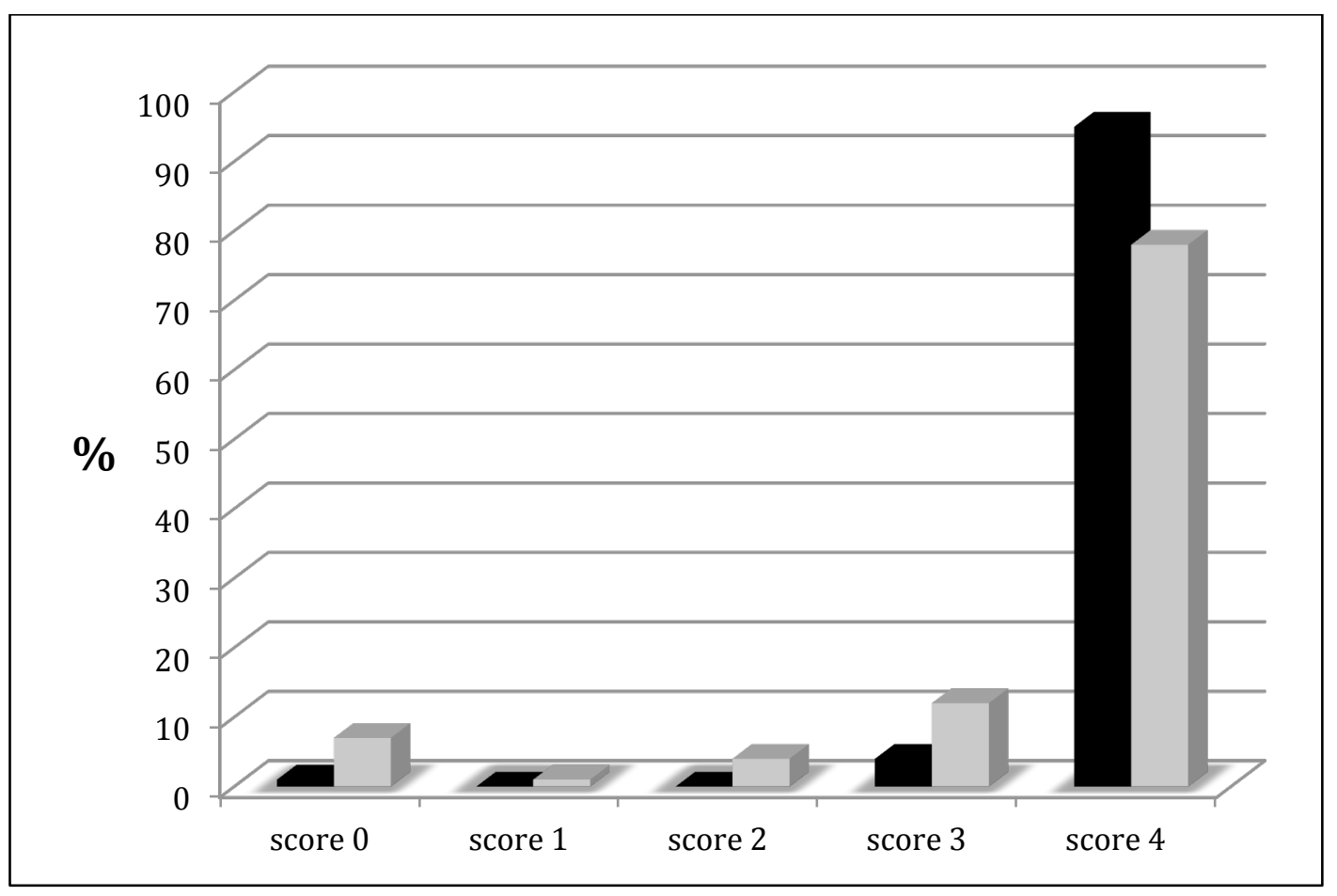

\begin{tabular}{|l|l|l|l|l|l|}
\hline Country & Mean & SD & t & df & p \\
\hline Whole & 3.7 & 0.9 & & & \\
\cline { 1 - 2 } & 3.9 & 0.4 & & & \\
\hline FR & 3.5 & 1.1 & -4.2 & 260.2 & 0.000004 \\
\hline
\end{tabular}


Figure 9: Scores for Section D - Question 3 (Black columns = U.K.; Grey columns = France) If you were told that your medical doctor (GP) had little or no experience of human dissection in today's medical course, would your confidence in him/her be: Greatly increased (0); Slightly increased (1); Not affected (2); Slightly diminished (3); Greatly diminished (4)

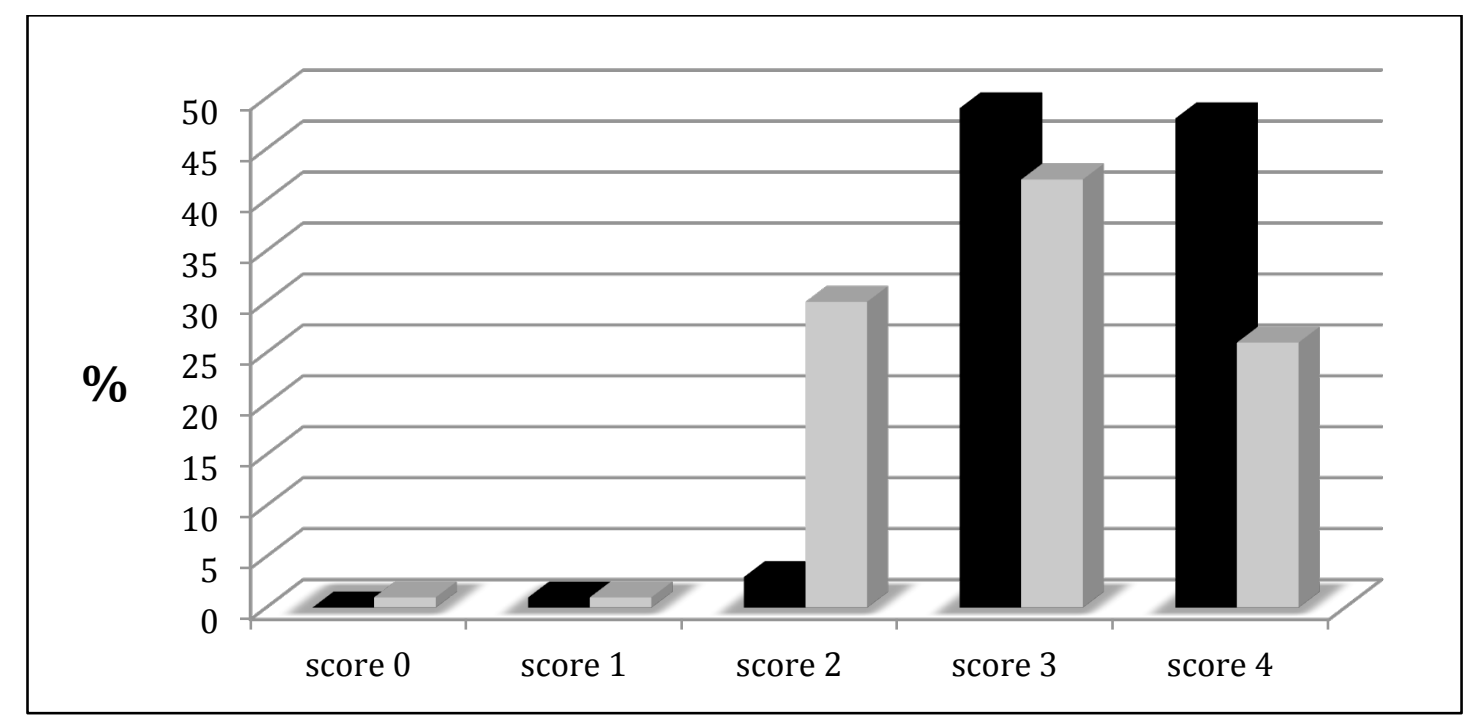

\begin{tabular}{|l|l|l|l|l|l|}
\hline Country & Mean & SD & t & df & p \\
\hline Whole & 3.1 & 0.8 & & & \\
\cline { 1 - 2 } & 4.4 & 0.6 & & & \\
\hline FR & 2.9 & 0.8 & -5.8 & 254.8 & 0.000000 \\
\hline
\end{tabular}


Figure 10: Scores for Section D - Question 4 (Black columns = U.K.; Grey columns = France) If you were told that your surgeon had little or no experience of human dissection in today's medical course, would your confidence in him/her be: Greatly increased (0); Slightly increased (1); Not affected (2); Slightly diminished (3); Greatly diminished (4)

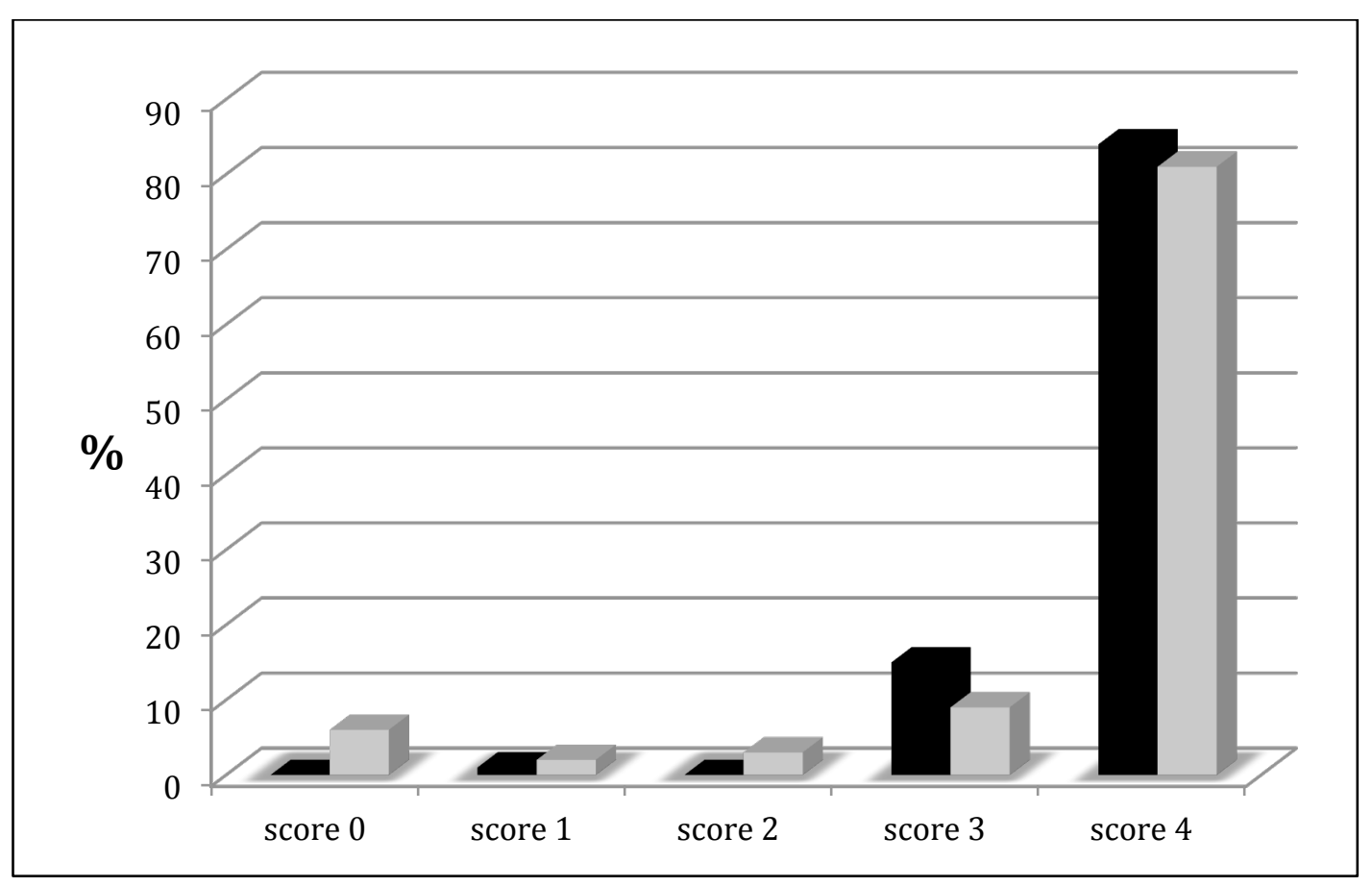

\begin{tabular}{|l|l|l|l|l|l|}
\hline Country & Mean & SD & t & df & p \\
\cline { 1 - 3 } Whole & 3.7 & 0.9 & & & \\
\cline { 1 - 3 } & 3.8 & 0.5 & & & \\
\hline FR & 3.6 & 1.1 & -2.8 & 267.6 & 0.005273 \\
\hline
\end{tabular}


Figure 11: Scores for Section D - Question 5 (Black columns = U.K.; Grey columns = France) If you were told that medical students were seeing hospital patients before they had much anatomical teaching, would your confidence in the medical profession be: Greatly increased (0); Slightly increased (1); Not affected (2); Slightly diminished (3); Greatly diminished (4)

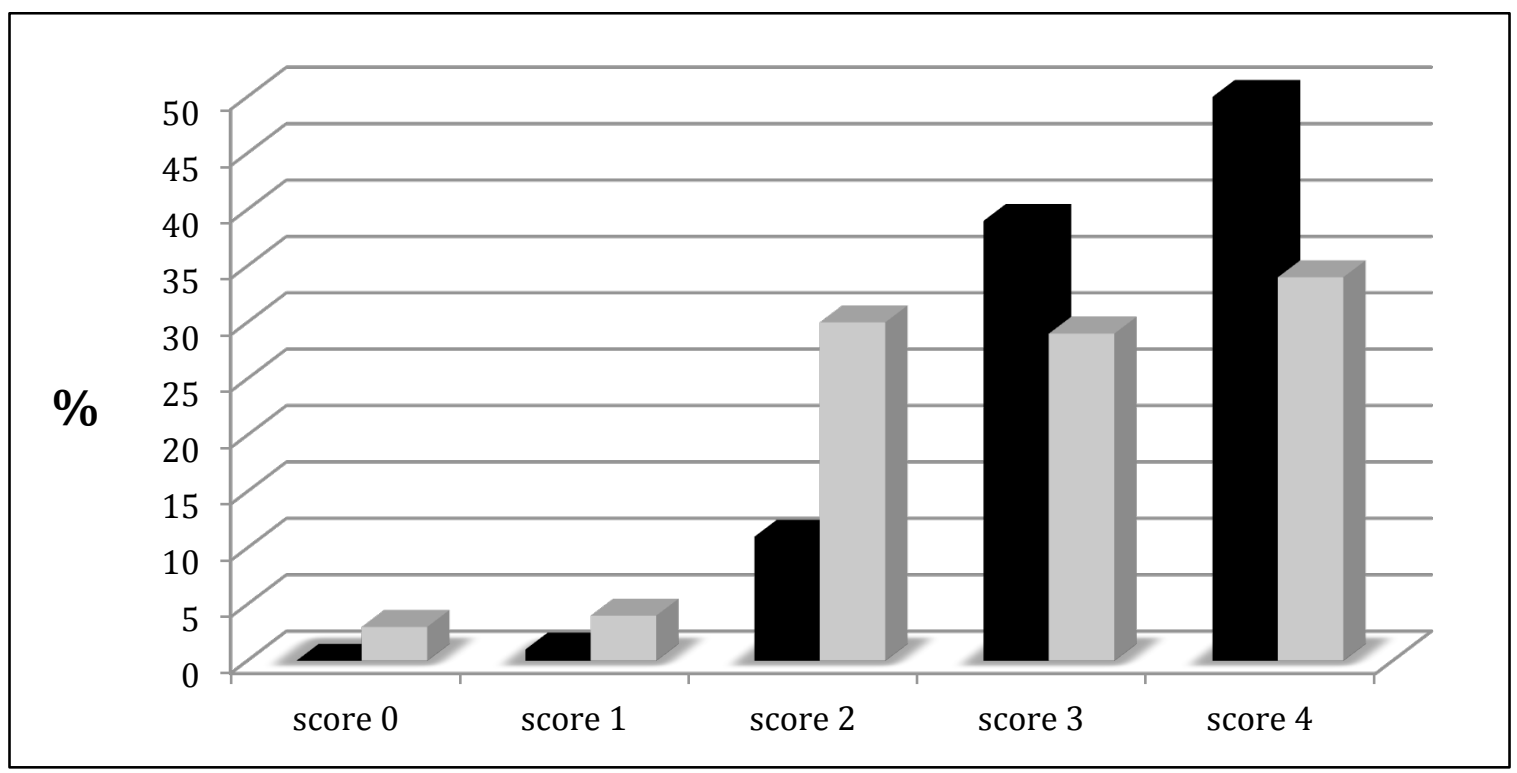

\begin{tabular}{|l|l|l|l|l|l|}
\hline Country & Mean & SD & t & df & p \\
\cline { 1 - 2 } Whole & 3.0 & 1.0 & & & \\
\cline { 1 - 3 } U.K. & 3.4 & 0.7 & & & \\
\cline { 1 - 2 } & 2.9 & 1.0 & -4.8 & 267.3 & 0.0000002 \\
\hline
\end{tabular}


Figure 12: Scores for Section D - Question 6 (Black columns = U.K.; Grey columns = France) In your view, with little anatomical training, what would you expect from the frequency of medical accidents: Greatly decreased (0); Slightly decreased (1); Not affected (2); Slightly increased (3); Greatly increased (4)

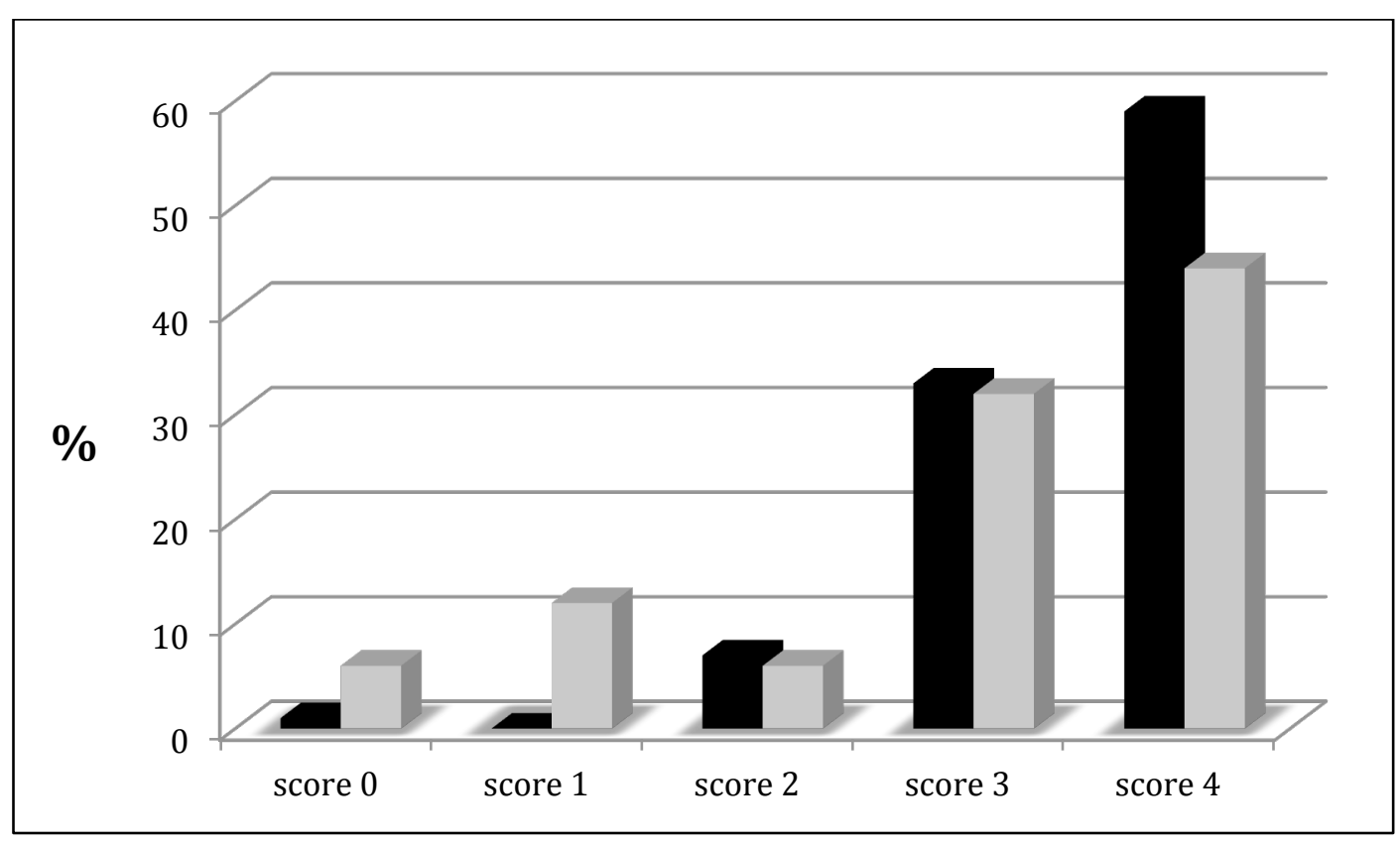

\begin{tabular}{|l|l|l|l|l|l|}
\hline Country & Mean & SD & t & df & p \\
\cline { 1 - 2 } Whole & 3.2 & 1.1 & & & \\
\cline { 1 - 2 } U.K. & 3.5 & 0.7 & & & \\
\cline { 1 - 2 } & 3.0 & 1.2 & -4.5 & 277.8 & 0.00000008 \\
\hline
\end{tabular}


Figure 13: Scores for Section D - Question 7 (Black columns = U.K.; Grey columns = France) In your view, with little anatomical training and experience of dissection, what would be the overall effect of your confidence in the medical profession: Greatly increased (0); Slightly increased (1); Not affected (2); Slightly diminished (3); Greatly diminished (4)

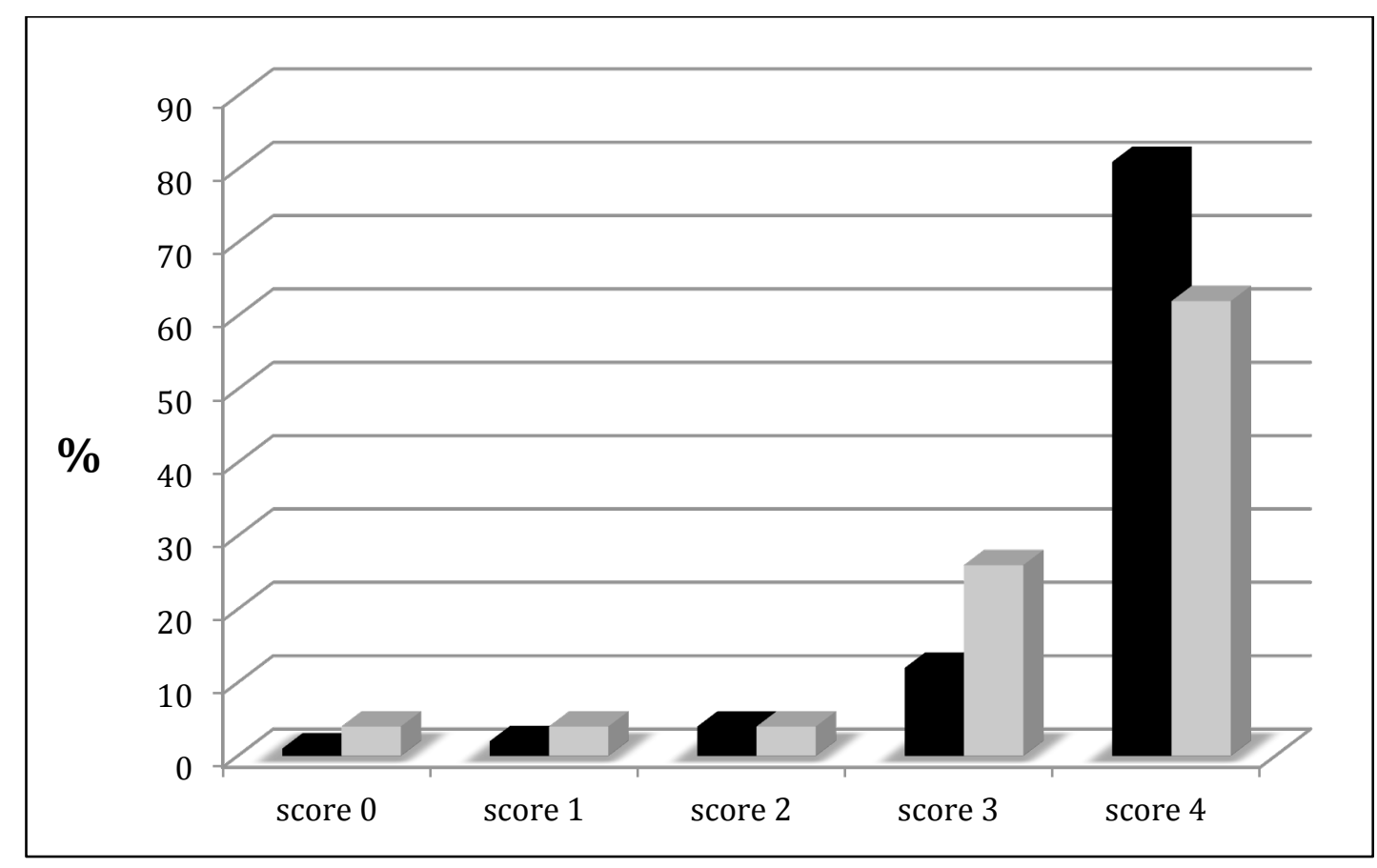

\begin{tabular}{|l|l|l|l|l|l|}
\hline Country & Mean & SD & t & df & p \\
\cline { 1 - 2 } & 3.5 & 0.9 & & & \\
\cline { 1 - 3 } U.K. & 3.7 & 0.7 & & & \\
\hline FR & 3.4 & 1.0 & -3.1 & 263.8 & 0.002241 \\
\hline
\end{tabular}


Figure 14
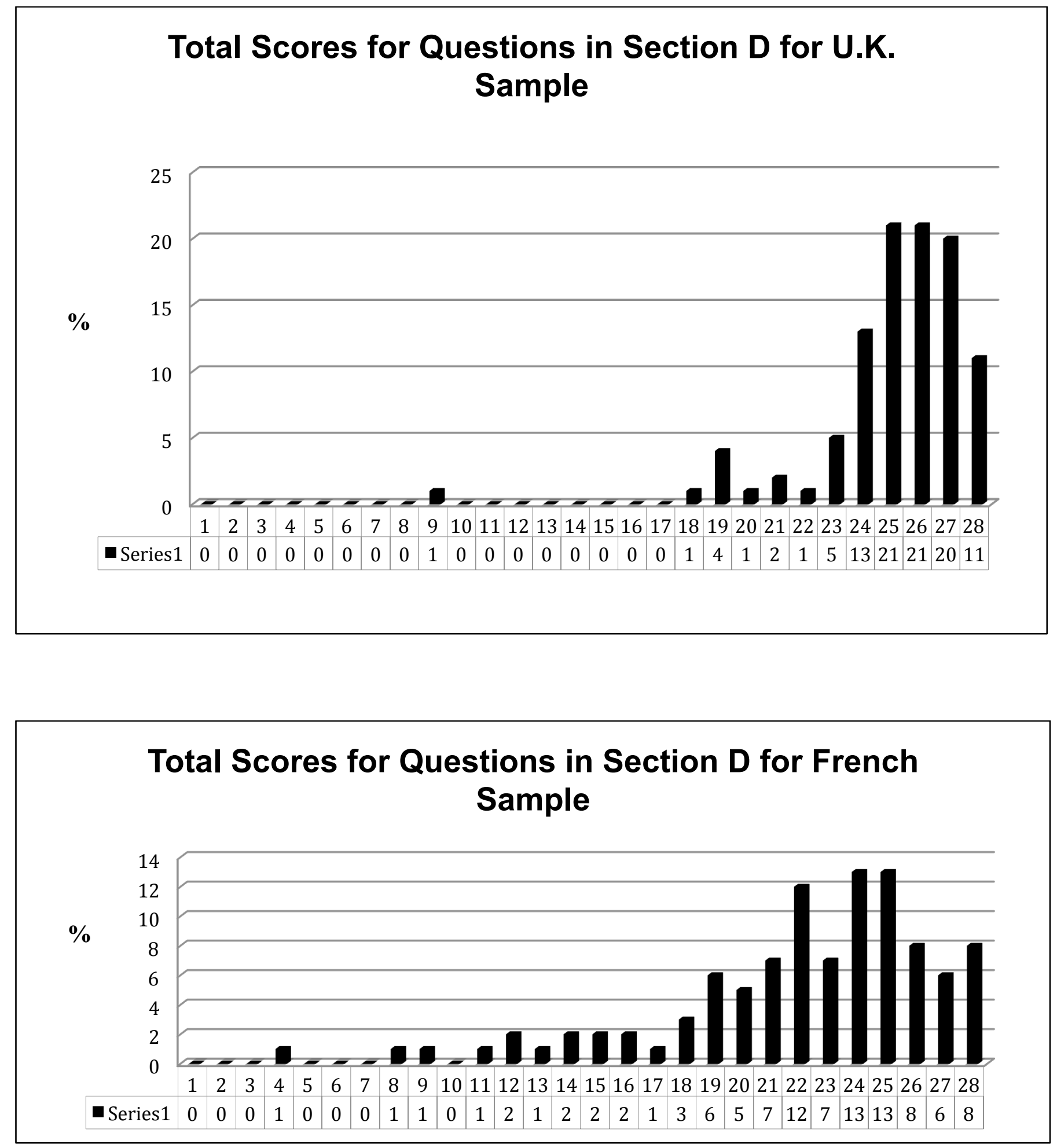

Figure 15 


\begin{tabular}{|c|c|}
\hline $\begin{array}{l}\text { MEDICAL PROFESSION } \\
\qquad \\
\text { DEANS, } \\
\text { EDUCATIONALISTS, } \\
\text { (TEACHERS) } \\
\qquad \\
\text { MEDICAL STUDENTS } \\
\square \\
\text { PATIENTS (PRESENT } \\
\text { OR FUTURE) }\end{array}$ & \begin{tabular}{|c} 
PATIENTS (PRESENT \\
OR FUTURE) \\
$\rrbracket$ \\
MEDICAL PROFESSION \\
$\mathbb{1}$ \\
DEANS, \\
EDUCATIONALISTS, \\
(TEACHERS) \\
$\rrbracket$ \\
MEDICAL STUDENTS
\end{tabular} \\
\hline
\end{tabular}

